ARTICLE

DOI: 10.1038/s41467-018-06002-w OPEN

\title{
Development of an antibody fragment that stabilizes GPCR/G-protein complexes
}

Shoji Maeda', Antoine Koehl ${ }^{2}$, Hugues Matile ${ }^{3}$, Hongli Hu,2, Daniel Hilger ${ }^{1}$, Gebhard F.X. Schertler ${ }^{4}$, Aashish Manglik ${ }^{5,6}$, Georgios Skiniotis (1) ${ }^{1,2}$, Roger J.P. Dawson (1D ${ }^{3}$ \& Brian K. Kobilka ${ }^{1}$

Single-particle cryo-electron microscopy (cryo-EM) has recently enabled high-resolution structure determination of numerous biological macromolecular complexes. Despite this progress, the application of high-resolution cryo-EM to G protein coupled receptors (GPCRs) in complex with heterotrimeric $G$ proteins remains challenging, owning to both the relative small size and the limited stability of these assemblies. Here we describe the development of antibody fragments that bind and stabilize GPCR-G protein complexes for the application of high-resolution cryo-EM. One antibody in particular, mAb16, stabilizes GPCR/G-protein complexes by recognizing an interface between $G \alpha$ and $G \beta \gamma$ subunits in the heterotrimer, and confers resistance to GTP $\gamma$ S-triggered dissociation. The unique recognition mode of this antibody makes it possible to transfer its binding and stabilizing effect to other G-protein subtypes through minimal protein engineering. This antibody fragment is thus a broadly applicable tool for structural studies of GPCR/G-protein complexes.

\footnotetext{
${ }^{1}$ Department of Molecular and Cellular Physiology, Stanford University School of Medicine, 279 Campus Drive, Stanford, CA 94305, USA. ${ }^{2}$ Department of Structural Biology, Stanford University School of Medicine, 279 Campus Drive, Stanford, CA 94305, USA. 3 Roche Pharma Research and Early Development, Therapeutic Modalities, Roche Innovation Center Basel, F.Hoffmann-La Roche Ltd, Grenzacherstrasse 124, 4070 Basel, Switzerland. ${ }^{4}$ Laboratory of Biomolecular Research, Paul Scherrer Institute, 5232 Villigen, Switzerland. ${ }^{5}$ Department of Pharmaceutical Chemistry, University of California San Francisco, 1700 4th Street, San Francisco, CA 94143, USA. ${ }^{6}$ Department of Anesthesia and Perioperative Care, University of California San Francisco, 17004 th Street, San Francisco, CA 94143, USA. Correspondence and requests for materials should be addressed to R.J.P.D. (email: roger.dawson@roche.com) or to B.K.K. (email: kobilka@stanford.edu)
} 
G protein coupled receptors (GPCRs) make up the largest receptor family in the human genome, comprising around 800 members. GPCRs are expressed ubiquitously and play essential roles of signal transduction in response to a wide variety of extracellular stimuli such as photons, ions, neurotransmitters, hormones and proteins. Given their numerous physiological roles, GPCRs are implicated in numerous diseases and $\sim 30 \%$ of marketed drugs are targeting this receptor family ${ }^{1}$. Recent advances in GPCR crystallography have led to high-resolution structures of G-protein ${ }^{2}$ and arrestin $^{3}$ complexes, which have enhanced our understanding of the structural details underlying ligand binding and signal transduction at the atomic level. The first crystal structure of a GPCR/G-protein complex was that of the $\beta_{2}$ adrenergic receptor in complex with stimulatory G-protein, $\mathrm{G}_{\mathrm{s}}\left(\beta_{2} \mathrm{AR} / \mathrm{G}_{\mathrm{s}}\right)^{2}$. This was later followed by the crystal structure of $A_{2 A}$ adenosine receptor in complex with miniG ${ }_{s}\left(A_{2 A} R / m_{i n i G}\right)$ in which a highly engineered $\mathrm{Ga}_{\mathrm{s}}$ that consists of only the $\mathrm{Ga}$ raslike domain was used in place of the full heterotrimer ${ }^{2,4}$. The fact that such drastic protein engineering is needed to obtain diffraction quality crystals reflects the difficulty inherent in GPCR-G-protein complex crystallography. Despite the technological advancement, crystallographic studies of these complexes remains extremely difficult. More recently, single-particle cryoelectron microscopy (cryo-EM) has emerged as an alternative technique with the ability to provide near-atomic resolution maps, as demonstrated for two class B GPCRs ${ }^{3,5,6}$ both in complex with $G_{s}$ : the glucagon-like peptide1 receptor/G $G_{s}$ (Glp$\left.1 R / G_{s}\right)^{6,7}$ as well as the calcitonin receptor $/ G_{s}\left(C T R / G_{s}\right)^{5}$. These studies have highlighted the possibility of employing cryo-EM to obtain the structures of GPCR-G protein complexes. Compared to class A GPCRs, class B receptors include a structured extracellular domain that may aid in particle alignment. Furthermore, for Gs proteins, $\mathrm{Nb}_{3} 5^{2}$ stabilizes these complexes against GTP $\gamma \mathrm{S}$ by stabilizing an interface between the Ras-like domain of the $G \alpha_{s}$ subunit and the G $\beta$ subunit. These factors make class B GPCR/Gs protein complexes more tractable targets for cryo-EM compared to class A or other G-protein subtype complexes.

Apart from the GPCR/G $\mathrm{G}_{\mathrm{s}}$ complex, the only structure available at high-resolution has been limited to the MetaII rhodopsin/ $\mathrm{Ga}$ where the last 11-amino-acid fragment of $\mathrm{G}_{\text {transducin }}$ was cocrystalized with the activated rhodopsin ${ }^{8}$. Although in silico analyses using this complex have provided insights into the conformational changes that allow $\mathrm{G}_{\mathrm{i}}$ coupling as well as general principles for $G$ protein coupling specificity ${ }^{9,10}$, experimental structures of other G-protein complexes are invaluable to understand how receptors selectively engage one G-protein subtype over others. G-protein mimetic nanobodies have been used as a surrogate to capture the active conformation of a receptor $^{11-14}$, but it may require an extensive effort to find such nanobodies and the trapped conformation may not necessarily represent the G-protein engaged state.

Here we describe the development of an antibody, termed $m A b 16$, that recognizes the heterotrimeric $G_{i / o}$ type $G$ protein and enhances the stability of GPCR-Gi/o complexes, while simultaneously adding an asymmetric feature that may aid with cryo-EM particle projection alignment. As antibodies typically bind to their targets in a rigid manner, such an antibody would be expected to enable structure determination of GPCR/G-protein complexes by cryo-EM. mAb16 recognizes a unique epitope, binding at the interface between the $\alpha$ and $\beta$ subunits of heterotrimeric $G_{i}$. While the antibody confers extra stability to GPCR/G $/ \mathrm{G}_{\mathrm{i} \text { o }}$ complex as well as increased resistance to GTP $\gamma \mathrm{S}$ triggered dissociation of the complex in a manner similar to Nb35 for $\mathrm{G}_{\mathrm{s}}, \mathrm{mAb} 16$ and Nb35 bind to completely different epitopes. We have recently succeeded in obtaining a near-atomic resolution map of the mu-opioid receptor $(\mu \mathrm{OR}) / \mathrm{G}_{\mathrm{i}}$ complex using this antibody fragment ${ }^{15}$. Although this antibody is specific against $\mathrm{G}_{\mathrm{i} / \mathrm{o}}$-family G-proteins, its ability to bind and stabilize the heterotrimer can be transferred to other G-protein subtypes through a simple protein engineering strategy.

\section{Results}

Selection of monoclonal antibodies. Despite exhaustive attempts to crystalize a complex between rhodopsin and heterotrimeric $\mathrm{G}_{\mathrm{i} 1}{ }^{16}$, we were unsuccessful in producing diffraction quality crystals. We presumed that this was due to the flexibility of the alpha-helical domain of $\mathrm{Ga}_{\mathrm{i} 1}$ as this domain separates from Raslike domain and becomes flexible upon receptor-mediated activation in the nucleotide-free state $e^{17,18}$. We then set out to discover antibodies that could reduce this flexibility and facilitate crystallographic and cryo-EM structural studies of the complex. Mice were immunized with purified rhodopsin/ $\mathrm{G}_{\mathrm{i} 1}$ complex and hybridoma cells were prepared from the isolated mice splenocytes. Clones that showed enzyme-linked immunosorbent assay (ELISA) and immunoprecipitation positive reaction were screened further using an analytical size-exclusion chromatography (SEC) assay with purified monoclonal antibodies. Most of the SEC-positive clones were $G \beta \gamma$-binders, reflecting that it is the most stable and rigid component of the complex (Fig. 1a, c). Interestingly, we found a single clone that binds and confers GTP $\gamma \mathrm{S}$ resistance to the rhodopsin $/ G_{i 1}$ complex (Fig. 1a, b). Based on the clone identification number, we named its antibody mAb16. Notably, this clone does not show binding to any single component of $G_{i 1}$, but binds specifically to the intact heterotrimeric form of $G_{i 1}$, suggesting that it binds a composite epitope at the interface between $\mathrm{G} \alpha_{\mathrm{i} 1}$ and $\mathrm{G} \beta \gamma$ subunits (Fig. 1c). We provide amino-acid sequence of mAb16 in the Supplementary Note 1.

Crystal structure of Gi1/scFv16. In order to better understand the recognition mode of mAb16, we crystallized a fully soluble heterotrimeric $G_{i 1}$ in complex with mAb16 fragments. We tried both a Fab fragment (Fab16) and single-chain variable fragment (scFv16) derived from mAb16. Both Gi1/Fab16 and Gi1/scFv16 complexes formed crystals but only the scFv16 version diffracted to high resolution, presumably due to the intrinsic flexibility of the linker between the variable and the constant domain of the $\mathrm{Fab}^{19}$. The crystal structure of the $\mathrm{G}_{\mathrm{i} 1} / \mathrm{scFv} 16$ complex was solved at $2.0 \AA$ by molecular replacement using $G_{i 1}$ (PDB ID: 1GP2) and an scFv fragment (PDB ID: 4NKD) as search models (Table 1). The overall structure of $G_{i 1}$ in complex with scFv16 is very similar to $G_{i 1}$ alone (Fig. 2a). The relative position of Ras-like domain and alpha-helical domain of $\mathrm{Ga}_{\mathrm{i} 1}$ moves closer to $\mathrm{G} \beta_{1}$ by a small rotation movement around the $a \mathrm{~N}-\mathrm{b} 1$ junction (Fig. 2b). This slight movement leads to two additional interactions between Thr182 of Gail and Asn119 of G $\beta_{1}$, and Arg205 of Gail and Thr143 of $G \beta_{1}$, located in Switch I and Switch II region, respectively (Fig. $2 \mathrm{~b}$ ). This could be due to the tighter association between these two subunits mediated by scFv16, although it may be the consequence of different crystal contacts between $G_{i 1}$ alone and $\mathrm{G}_{\mathrm{i} 1} / \mathrm{scFv} 16$. The structure of the $\mathrm{G}_{\mathrm{i} 1} / \mathrm{scFv} 16$ complex shows that scFv16 recognizes an epitope composed of the terminal part of the $\alpha \mathrm{N}$ helix of $\mathrm{Ga}_{\mathrm{i} 1}$ as well as part of the $\mathrm{G} \beta_{1}$ subunit (Fig. $2 \mathrm{c}$, Supplementary Fig. 1). The complementarity-determining region 3 of the heavy chain (CDR-H3) extends to interact with G $\beta_{1}$ with its tip and $\mathrm{Ga}_{\mathrm{i} 1}$ with its side. CDR2-H2 and CDR-H1 support the interaction with $G \alpha_{i 1}$ and $G \beta_{1}$, respectively by making hydrogen bonds and van der Waals contacts. CDR-L1 is exceptionally long and makes extensive contact with the edge of the $a \mathrm{~N}$ helix together with CDR-L3 (Fig. 2c). There is no obvious interaction between scFv16 and $\mathrm{G} \gamma_{2}$ subunit. 



Fig. 1 Isolation of mAb16 and its binding profile to each component. a Analytical SEC of rhodopsin/ $G_{i 1}$ with each antibody. Rhodopsin/ $G_{i 1}$ runs at $8.2 \mathrm{~mL}$ and each $\mathrm{mAb}$ alone runs $8.4-9 \mathrm{~mL}(\mathbf{c})$. Rhodopsin/ $\mathrm{G}_{\mathrm{i1}}$ bound to $\mathrm{mAb}$ makes higher molecular weight product and migrates at the elution volume of 6-7 $\mathrm{mL}$ depending on the $\mathrm{mAb}$. $\mathbf{b}$ Analytical SEC of rhodopsin $/ \mathrm{G}_{\mathrm{i1}}$ with each antibody following to GTP $\gamma \mathrm{S}$ treatment. Intact complex remains at 6-7 $\mathrm{mL}$ only in the mAb16 condition. $\mathbf{c}$ Analytical SEC of individual component of rhodopsin/ $\mathrm{G}_{\mathrm{i} 1}$ or heterotrimeric $\mathrm{G}_{\mathrm{i} 1}$ with each antibody. Top left: Binding experiment with Goi1 subunit and each mAb. The peak of Goi1 at $11 \mathrm{~mL}$ stays intact indicating there is no binding with each mAb. Top right: Binding experiment with opsin. Both $\mathrm{mAb}$ peaks and Opsin peak (at $9.5 \mathrm{~mL}$ ) stays intact. Bottom left: Binding experiment with $\mathrm{G} \beta \gamma$ subunit. The peak of $\mathrm{G} \beta \gamma$ at $11.2 \mathrm{~mL}$ disappears upon incubating with mAbs except mAb16 and each mAb peak shifts towards left compared to the ones with Gai1 or opsin indicating those mAbs recognize $\mathrm{G} \beta \gamma$ subunit as an epitope. Bottom right: Binding experiment with heterotrimeric Gi1

\begin{tabular}{|ll|}
\hline Table 1 Data collection and refinement statistics \\
& Gi1/scFv16 ${ }^{\mathbf{a}}$ \\
\hline Data collection & \\
Space group & $P 222_{1}$ \\
Cell dimensions $(\sigma)$ & \\
$a, b, c(\AA)$ & $58.51,104.74,211.82$ \\
$\alpha, \beta, \gamma\left({ }^{\circ}\right)$ & $90.00,90.00,90.00$ \\
Resolution $(\AA)$ & $39.26-2.00(2.07-2.00)^{b}$ \\
$R_{\text {sym } \text { or } R_{\text {merge }}}$ & $0.176(0.888)$ \\
/ $\sigma$ l & $9.91(0.73)$ \\
Completeness $(\%)$ & $99.16(99.47)$ \\
Redundancy & $4.6(4.8)$ \\
Refinement & \\
Resolution $(\AA)$ & $39.26-2.00(2.07-2.00)$ \\
No. reflections & $88,191(8710)$ \\
$R_{\text {work }} / R_{\text {free }}$ & $0.1746 / 0.2097(0.2682 / 0.2940)$ \\
No. atoms & \\
Protein & 7567 \\
Ligand/ion & 41 \\
Water & 628 \\
$B$-factors $(\AA 2)$ & \\
Protein & 47.08 \\
Ligand/ion & 31.55 \\
Water & 51.44 \\
R.m.s. deviations & \\
Bond lengths $(\AA)$ & 0.007 \\
Bond angles $\left({ }^{\circ}\right)$ & 1.19 \\
\hline
\end{tabular}

aThe data set was collected from one single crystal

bvalues in parentheses are for highest-resolution shell

As the a subunits of all $\mathrm{G}_{\mathrm{i} / \mathrm{o}}$ family members have high sequence similarity at the epitope residues in the $a \mathrm{~N}$ helix (Fig. 3a) and can form a complex with $G \beta_{1} \gamma_{2}$, we expected that Fab16 would bind to all $G_{i / o}$ family proteins. Using analytical fluorescent SEC, we show that Fab16 can bind to five different $G_{i /}$ o type G-proteins but not $\mathrm{G}_{\mathrm{s}}$, as it has poor sequence similarity to $\mathrm{G}_{\mathrm{i} / \mathrm{o}}$ members at this epitope region (Fig. 3b).

Application to other GPCR-G $\mathrm{G}_{\mathrm{i} / \mathrm{o}}$ complexes. Since Fab16 was initially isolated as a stabilizing agent that confers resistance to GTP $\gamma S$ triggered dissociation to a rhodopsin $/ G_{i 1}$ complex and was later found to bind to a panel of $G_{i / o}$ family members, we investigated whether it confers the same GTP $\gamma S$ resistance to other $\mathrm{G}_{\mathrm{i} / \mathrm{o}}$ type GPCR complexes. We chose a $\mu$-opioid receptor/ $\mathrm{G}_{\mathrm{i} 1}\left(\mu \mathrm{OR} / \mathrm{G}_{\mathrm{i} 1}\right)$ and an $\mathrm{M}_{2}$ muscarinic acetylcholine receptor/ $\mathrm{G}_{\mathrm{oA}}$ $\left(\mathrm{M}_{2} \mathrm{R} / \mathrm{G}_{\mathrm{OA}}\right)$ as representative family $A \mathrm{G}_{\mathrm{i} / \mathrm{o}}$-coupling GPCR complexes. Purified $\mu O R / G_{i 1}$ or $M_{2} R / G_{o A}$ complex solubilized in detergent was incubated with GTP $\gamma \mathrm{S}$ in the presence or absence of Fab16, then analysed for dissociation by analytical SEC. Both $\mu \mathrm{OR} / \mathrm{G}_{\mathrm{i} 1}$ and $\mathrm{M}_{2} \mathrm{R} / \mathrm{G}_{\mathrm{oA}}$ complexes showed a leftward peak shift upon incubating with Fab16, indicating its binding and also became GTP $\gamma$ S resistant, as they showed much less dissociation in the presence of Fab16 than the complex alone (Fig. 3c). These data with $\mathrm{GPCR} / \mathrm{G}_{\mathrm{i} / \mathrm{o}}$ complexes are consistent with the binding experiments of Fab16 with G-protein alone, and indicate that it stabilizes $G_{i / o}$ type GPCR complexes in general. In order to show the applicability of scFv16 to structural analysis of GPCR-G protein complexes, we have recently solved a near-atomic resolution map of $\mu \mathrm{OR} / \mathrm{G}_{\mathrm{i} 1}$ complex using $\mathrm{scFv} 16^{15}$. The presence of scFv16 enhanced complex stability towards specimen vitrification for cryo-EM, thereby enabling quality single-particle reconstructions.

Influence of Fab16 on nucleotide binding. In order to further investigate $\mathrm{mAb} 16$ for its protection mechanism against GTP $\gamma \mathrm{S}$, we monitored the binding kinetics of GTP $\gamma S$ to nucleotide-free $\mathrm{M}_{2} \mathrm{R} / \mathrm{G}_{\mathrm{oA}}$ complex. In the absence of Fab16, BODIPY-FL-GTP $\gamma \mathrm{S}$, a fluorescent analogue of GTP $\gamma \mathrm{S}$, binds to the complex with fast kinetics reflecting its ability to bind and trigger the dissociation of the complex. In contrast, BODIPY-FL-GTP $\gamma \mathrm{S}$ binds to $\mathrm{M}_{2} \mathrm{R} / \mathrm{G}_{\mathrm{oA}} /$ Fab16 complex $\sim 70$ times slower and to a much lower extent 
a

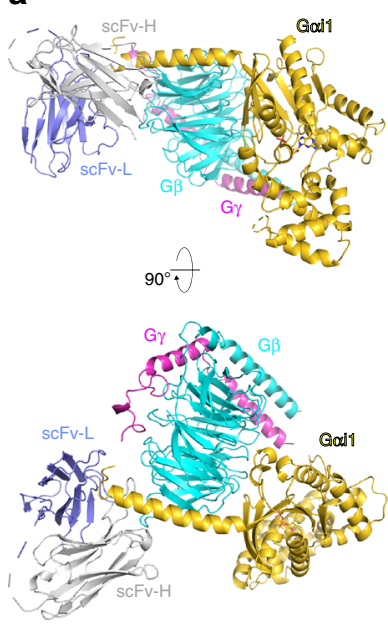

b



c

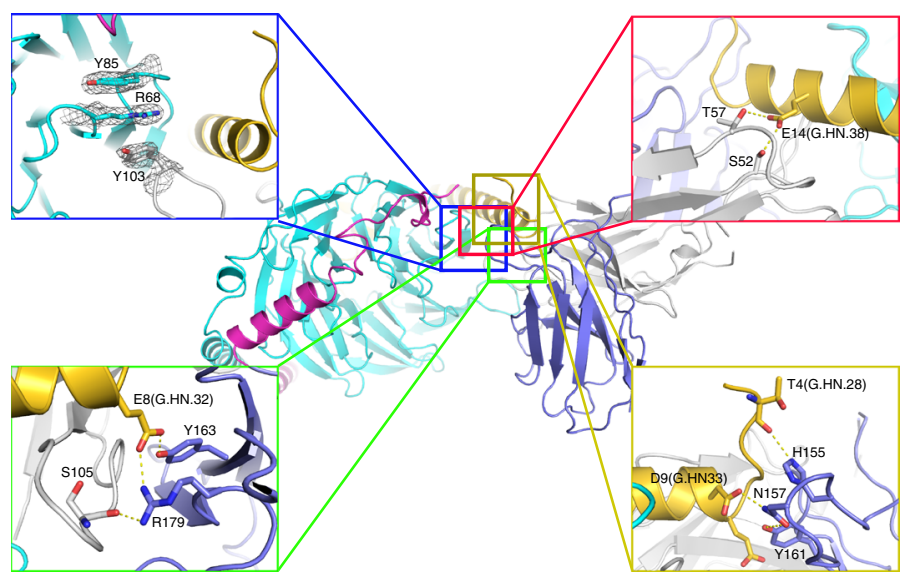

Fig. 2 Crystal structure of $\mathrm{G}_{\mathrm{i} 1} / \mathrm{scFv16}$ and characterization of Fab16. a Overall structure of $\mathrm{Gi1} / \mathrm{scFv} 16$ complex. Cartoon representation with $\mathrm{G}_{\mathrm{i} 1}$ in gold, $\mathrm{G} \beta$ in cyan, $\mathrm{G} \gamma$ in magenta, scFv-heavy chain in light grey and scFv-light chain in light blue. b Superposition of $\mathrm{G}_{\mathrm{i} 1} / \mathrm{scFv} 16$ structure onto $\mathrm{G}_{\mathrm{i}}$ (PDB: $1 \mathrm{GP2}$ ) based on alignment of $\mathrm{G} \beta \gamma$ subunits. $\mathrm{G} \alpha_{\mathrm{i} 1}$ (1GP2) in grey and $\mathrm{G}_{\mathrm{i} 1} / \mathrm{scFv16}$ in the same colour code as in a. For clarity, $\mathrm{G} \beta \gamma$ subunits and scFv16 is shown as transparent cartoon. Arrows show a slight rotational displacement of $\mathrm{G} \alpha{ }_{\mathrm{i} 1}$ towards $\mathrm{G} \beta_{1}$ compared to $\mathrm{Gi} 1$ alone. Additional interactions are formed between switch I and switch II of $G \alpha_{i 1}$ and $G \beta_{1}$. c Interaction between $G_{i 1}$ and scFv16. The residues participating in the interactions are depicted with stick models in the expanded panels. Residue numbers are shown with Common $\mathrm{G} \alpha$ Numbering (CGN) code for $\mathrm{G}_{\mathrm{i1}} 42$

(Fig. 4a). On the other hand, the binding of GDP is only modestly affected when the complex is bound to Fab16 (Fig. 4a). Next we examined the basal nucleotide exchange rate of Gil and Gi1/ Fab16 under conditions where GDP release is rate-limiting (Fig. 4b). Fab16-bound Gil releases GDP $\sim 1.5$ to 2 -fold slower than Gil alone (Table 2). These findings suggest that in the absence of a coupled GPCR, Fab16 stabilizes the heterotrimer in its GDP-bound conformation. As a comparison, we examined the effect of Nb35 that was originally developed against the $\beta_{2} A R / G_{s}$ complex ${ }^{2}$. Structurally, it binds at the interface between switch II and helix III of Gas and $G \beta_{1}$, and has been characterized to provide GTP $\gamma S$ resistance to a GPCR $/ \mathrm{G}_{\mathrm{s}}$ complex. It's been used for structural studies of all GPCR/ $\mathrm{G}_{\mathrm{s}}$-type complexes both in crystallography and cryo-EM so far $^{2,5-7}$. We monitored the binding kinetics of GTP $\gamma S$ and GDP to the nucleotide-free $\beta_{2} A R /$ $\mathrm{G}_{\mathrm{s}}$ complex. BODIPY-FL-GTP $\gamma \mathrm{S}$ binds to the complex with fast kinetics in the absence of Nb35 but becomes extremely slow or negligible when bound with $\mathrm{Nb35}$ (Fig. 4c), presumably due to the inhibition of the conformational change in switch II and switch III. BODIPY-FL-GDP showed no detectable binding to the complex alone or to the complex bound with Nb35 (Fig. 4c).

Generalization of mAb16 binding to other G-protein subtypes. Because mAb16's epitope is located on a short stretch of the $a \mathrm{~N}$ helix of the Ga subunit (Figs. 2a, b and 3a) as well as a small part of the $G \beta_{1}$ subunit that can complex with all $G \alpha$-protein subtypes, we sought to engineer the $\alpha \mathrm{N}$ helix of the other G-protein $\alpha$ subunits in order to generalize scFv16 binding to all G-protein subtypes. Starting with the $\mathrm{Ga}_{\mathrm{s}}$ subunit, we generated a chimera in which the $a \mathrm{~N}$ helix was replaced by the equivalent region of $\mathrm{Ga}_{\mathrm{i}}\left(\mathrm{Ga}_{\mathrm{si}} \mathrm{N}\right.$; residues $1-38$ of Gas replaced by residues $1-31$ of Gail) (Fig. 5a). The $\mathrm{Ga}_{\mathrm{si}} \mathrm{N}$ protein forms a heterotrimer with the $\mathrm{G} \beta \gamma$ subunit and forms a stable complex with the $\beta_{2} \mathrm{AR}$ (Fig. 5b). The $\beta_{2} \mathrm{AR} / \mathrm{G}_{\mathrm{si}} \mathrm{N}$ complex can bind Fab16 and is largely protected from dissociation induced by GTP $\gamma$, whereas $\beta 2 \mathrm{AR} / \mathrm{GsiN}$ complex alone dissociated almost completely under the same condition (Fig. 5b). We then used the same engineering approach to transfer Fab16 binding ability to $G_{11}, a G_{q}$ family member, and replaced the $\alpha \mathrm{N}$ helix of $\mathrm{Ga}_{11}$ with that from $\mathrm{Ga}_{\mathrm{i} 1}\left(\mathrm{Ga}_{11 \mathrm{i}} \mathrm{N}\right.$, residues 1-35 of $\mathrm{Ga}_{11}$ replaced by residues 1-29 of $\mathrm{Ga}_{\mathrm{i} 1}$ ) (Fig. 5a).
The $G a_{11 i} \mathrm{~N}$ protein forms a heterotrimer with $\mathrm{G} \beta \gamma$ subunit and couples to form a stable complex with the $M_{1}$ muscarinic acetylcholine receptor $\left(M_{1} R\right.$ ) (Fig. $5 c$ ). The $M_{1} R / G_{11 i} N$ complex alone dissociates upon incubation with GTP $\gamma \mathrm{S}$, whereas the $\mathrm{M}_{1} \mathrm{R}$ / $\mathrm{G}_{11 \mathrm{i}} \mathrm{N}$ complex bound to Fab16 showed GTP $\gamma \mathrm{S}$ resistance (Fig. 5c) consistent with $\mathrm{G}_{\mathrm{i} / \mathrm{o}}$ and $\mathrm{G}_{\mathrm{si}} \mathrm{N}$ complexes. Negative stain EM visualization of the $M_{1} R / G_{11 i} N$ complex reveals a monodisperse sample (Fig. 5d). These results demonstrate that Fab16 (or scFv16) can be used as a tool with broad variety of GPCR/Gprotein complexes by substituting the $\alpha \mathrm{N}$ helix of other $\mathrm{Ga}$ subunit with equivalent region of Gail. Scanning the chimera junction between $\mathrm{Ga}_{11}$ and $\mathrm{Ga}_{\mathrm{i} 1}$ shows that a smaller substitution in the middle of the $a \mathrm{~N}$ helix is still tolerated for the expression and the heterotrimer formation (Supplementary Fig. 2a). When replaced with the equivalent residues with this minimal chimeric region (residues 1-18 of Gail), both $G_{s}$ and $G_{11}$ are enabled to bind Fab16 and form stable complexes with respective GPCRs (Supplementary Fig. 2b, c.) The same minimal region when transferred to $\mathrm{G}_{12}$ also enables Fab16 binding (Supplementary Fig. 2d). The binding interface of G $\beta 1$ subunit to scFv16 is limited compared to $\mathrm{Ga}$ subunit in the crystal structure. These residues are mostly conserved among $G \beta$ family members except G $\beta 5$ (Supplementary Fig. 3). There is no direct interaction between $\mathrm{G} \gamma 2$ and scFv16 in the crystal structure. The fact that mAb16 was originally raised against and indeed binds to Rhodopsin/Gil that is composed of $\mathrm{G} \gamma 1$ from the native bovine retina and still binds G-proteins or GPCR/G-protein complexes composed of G $\gamma 2$ indicates that Fab/scFv16 binds to the heterotrimeric G-protein regardless of the composition of the $\gamma$-subunit. Therefore, the binding ability to Fab16 is transferable to broad range of Gprotein family members with minimal chimeric constructs. We provide amino-acid sequences of G-protein chimera constructs in the Supplementary Note 2 as well as the primers used for the construction in the Supplementary Table.

\section{Discussion}

In this work, we have developed a unique antibody fragment that recognizes an interface on heterotrimeric $\mathrm{G}_{\mathrm{i} 1}$. The antibody confers the GPCR- $\mathrm{G}_{\mathrm{i} / \mathrm{o}}$ complexes the resistance to GTP $\gamma \mathrm{S}$ induced dissociation. This property is also observed with formerly 
a

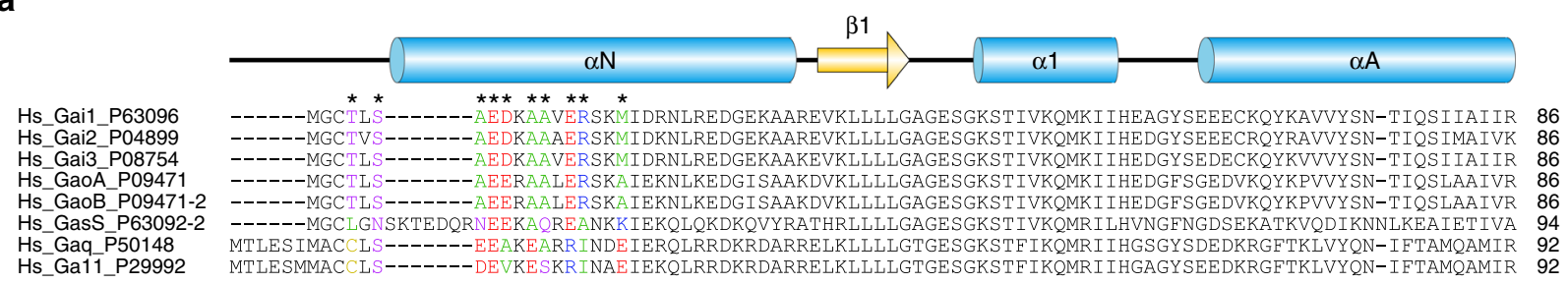

b



C

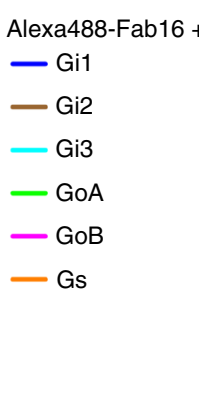





Fig. 3 Sequence alignment of G-protein family members and binding profile of Fab16. a Multiple sequence alignment of amino-termini of representative G $\alpha$ subunits from human. UniProt numbers are provided after each G-protein subtype name. Secondary structures are shown as cylinder (helix) and arrow (strand). The asterisks indicate the residues in contact with scFv16 in $\mathrm{G \alpha}_{\mathrm{i} 1}$ and those corresponding residues are coloured according to their property: Positive in blue, negative in red, hydrophobic in green, polar in purple, cysteine in yellow. b Fluorescent SEC analysis of binding of the fluorescently labelled Fab16 with G-protein family members. c Analytical tryptophane fluorescent $S E C$ of $\mu O R / G_{i 1}$ and $M_{2} R / G_{\circ A}$ with $G T P \gamma S$ in the presence or absence of Fab16. Each complex alone runs around $12.2 \mathrm{~mL}$. Upon binding to Fab16, they run at $11.4 \mathrm{~mL}$ or $11.6 \mathrm{~mL}$ indicating the binding of Fab16 to these GPCR/G-protein complexes. Excess free Fab16 runs at $16.1 \mathrm{~mL}$. Dissociated components upon incubating with GTP $\gamma \mathrm{S}$ show smaller peaks at $13.5-16 \mathrm{~mL}$

identified $\mathrm{Nb} 35$ for Gs complexes ${ }^{2}$. Nb35 and mAb16 engage distinct epitopes at the G-protein interface: $\mathrm{Nb} 35$ binds at the switch II and $\alpha$ III helix of $G \alpha_{s}$ and $G \beta$, while mAb16 engages the $\alpha \mathrm{N}$ helix of $\mathrm{Ga}_{\mathrm{i} 1}$ and $\mathrm{G} \beta$. The switch II region adopts a distinct conformation upon binding of GTP $\gamma \mathrm{S}$ compared to the nucleotide-free or GDP-bound state observed in the crystal structures as well as in the EPR spectroscopic measurement $t^{2,20-23}$. $\mathrm{Nb} 35$ is reported to suppress nucleotide exchange turnover of the $\mathrm{CTR} / \mathrm{G}_{\mathrm{S}}$ complex ${ }^{5}$ and indeed it prevents GTP $\gamma \mathrm{S}$ binding to the $\beta 2 A R / G_{s}$ complex (Fig. $4 c$ ), which we presume due to the fixed conformation of the switch II in the nucleotide-free state and steric clash of the switch III with Nb35. On the other hand, mAb16 binds $40 \AA$ away from the nucleotide-binding pocket with no direct contact with this region yet prevents the binding of GTP $\gamma \mathrm{S}$ to the nucleotide-free GPCR/G-protein complex (Fig. 4a) and helps heterotrimeric $\mathrm{G}_{\mathrm{i} 1}$ to retain GDP in the nucleotidebinding pocket (Fig. $4 \mathrm{~b}$ ). It has been reported that heterotrimer formation rigidifies the switch II region that is in direct contact with $G \beta$ subunit ${ }^{23}$. Thus, by stabilizing interactions between the $\mathrm{G} \beta$ subunit and switch II, mAb16 prevents GTP $\gamma$ S binding to the empty pocket. This may also explain the slower GDP release as $\mathrm{G} \beta$ subunit functions as a GDP dissociation inhibitor $(\mathrm{GDI})^{24}$. Additional interactions formed between switch I, II and $G \beta_{1}$ subunit upon scFv16 binding supports this idea (Fig. 2b). Another possibility would be inferred from HDX-MS measurements that revealed the dynamic nature of $\alpha \mathrm{N}-\beta 1$ junction of $\mathrm{G}_{s}$ during the complex formation with $\beta 2 \mathrm{AR}$ and the dissociation upon addition of GDP/AlF4 $4^{25}$. Binding of mAb16 would tighten the association of $\alpha \mathrm{N}$ helix with $\mathrm{G} \beta$ subunit and concomitantly reduce the dynamics of $\alpha \mathrm{N}-\beta 1$ junction, which may influence the binding of nucleotide through the $\beta 1$-strand and the P-loop that is in direct contact with nucleotide. Previous work showing that binding of GTP $\gamma S$ triggers release of $\alpha \mathrm{N}$ helix from $G \beta$ and promotes its unfolding ${ }^{26}$ indicates that there could be an allosteric effect between the nucleotide-binding pocket and $\alpha \mathrm{N}$ helix.

Contrary to the large diversity of different GPCR genes in the human genome, there are only four major G-protein family members: $G_{s}, G_{i / o}, G_{q / 11}$ and $G_{12 / 13}{ }^{27}$. Among them $G_{i / o}$ is the most broadly coupling G-protein ${ }^{10}$. mAb16 is originally raised against rhodopsin $/ \mathrm{G}_{i 1}$ complex and binds rhodopsin $/ \mathrm{G}_{i 1}, \mu \mathrm{OR} /$ $G_{i 1}$ and $M_{2} R / G_{o A}$ complexes, suggesting that it likely binds all $\mathrm{G}_{\mathrm{i} / \mathrm{o}}$ type complexes, according to the sequence similarity of the epitope residues and the binding profile of individual G-protein alone (Fig. 3b). In contrast, the binding interface of $\mathrm{Ga}_{\mathrm{s}}$ to $\mathrm{Nb} 35$ is not conserved among $\mathrm{Ga}$ subtypes; therefore it would require elaborate protein engineering to transfer the binding surface to 
a
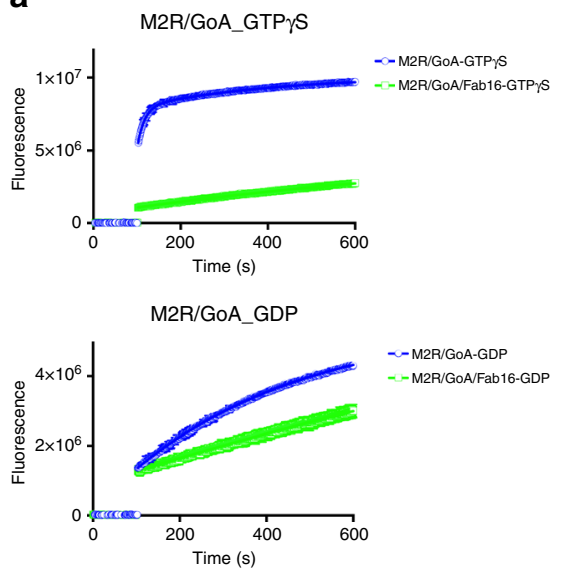

b
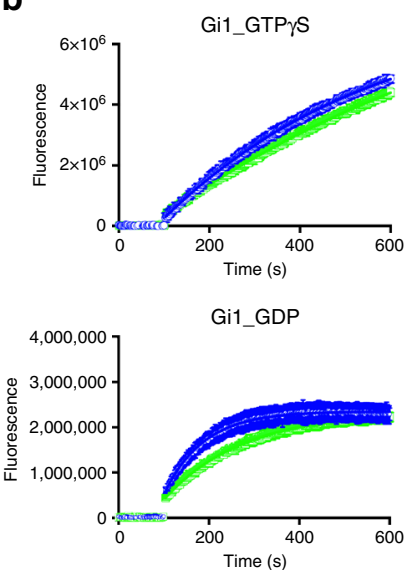

C

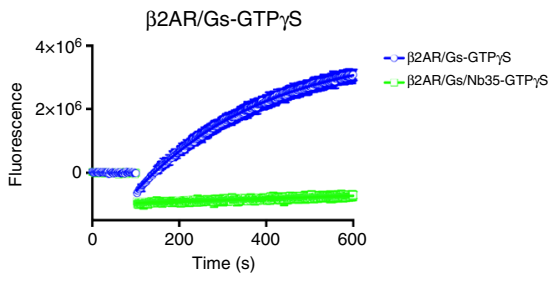

$\beta 2 A R / G s \_G D P$
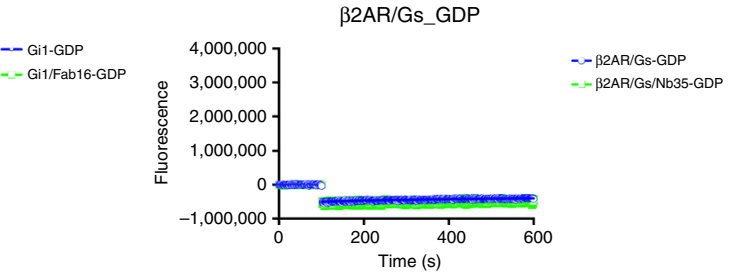

Fig. 4 Nucleotide-binding kinetics. a Influence of Fab16 on the nucleotide-binding kinetics of the purified $M_{2} R / G_{\circ A}$ complex. Nucleotide binding was monitored by using BODIPY-FL-GTPYS or BODIPY-FL-GDP. $\mathbf{b}$ Influence of Fab16 on the nucleotide release kinetics of $\mathrm{G}_{\mathrm{il}}$. GDP release was monitored by BODIPY-FL-GTPYS- or BODIPY-FL-GDP-binding kinetics under conditions where GDP release is the rate-limiting step. c Nucleotide binding to $\beta 2 A R / G_{s}$ complex in the presence or absence of Nb35. The curves represent the mean \pm standard error of three experiments

Table 2 Effect of Fab16 or Nb35 on the nucleotide-binding/releasing rate

$\begin{array}{ll} & \text { M2R/GoA }+ \text { GTP } \boldsymbol{\gamma} \mathbf{S} \\ k(1 / s) & 0.061 \pm 0.002 \text { (fast }^{\mathrm{a}} \\ k(1 / \mathrm{s}) & 0.0032 \pm 0.0002(\text { slow })^{\mathrm{a}} \\ & \text { Gi1 }+\mathbf{G T P} \boldsymbol{\gamma} \mathbf{S} \\ k(1 / \mathrm{s}) & 0.00206 \pm 0.00003 \\ & \mathbf{B}_{\mathbf{2}} \mathbf{A R} / \mathbf{G}_{\mathbf{s}}+\mathbf{G T P} \mathbf{S} \mathbf{S} \\ k(1 / \mathrm{s}) & 0.00327 \pm 0.00005\end{array}$

M2R/GoA + Fab16 + GTP $\gamma$ S

$0.00092 \pm 0.00004$

$\mathbf{G i 1}+\mathbf{F a b 1 6}+\mathbf{G T P} \boldsymbol{\gamma} \mathbf{S}$

$0.00116 \pm 0.00003$

$\boldsymbol{\beta}_{\mathbf{2}} \mathbf{A R} / \mathbf{G}_{\mathbf{s}}+\mathbf{N b 3 5}+\mathbf{G T P} \gamma \mathbf{S}$

ND

\begin{abstract}
M2R/GoA + GDP
$0.00244 \pm 0.00003$
\end{abstract}

M2R/GoA + Fab16 + GDP

$0.00042 \pm 0.00009$

Gi1 + GDP

$0.0115 \pm 0.0002$

$\boldsymbol{\beta}_{\mathbf{2}} \mathbf{A R} / \mathbf{G}_{\mathbf{s}}+\mathbf{G D P}$

ND
$\mathbf{G i 1}+\mathbf{G a b 1 6}+\mathbf{G D P}$

$0.00572 \pm 0.00007$

$\boldsymbol{\beta}_{\mathbf{2}} \mathbf{A R} / \mathbf{G}_{\mathbf{s}}+\mathbf{N b 3 5}+\mathbf{G D P}$ $\mathrm{ND}$

All values are expressed as mean \pm s.e.m. of triplicate experiments

aThe binding kinetics was best fit and analysed by two phase association. The fraction corresponding to the fast component is $0.526 \pm 0.005$

other family members or to evolve the nanobody itself. On the other hand, the binding surface of $\mathrm{Ga}_{\mathrm{i} 1}$ to mAb16 is located in a small stretch of the $\alpha \mathrm{N}$ helix. Since the $\alpha \mathrm{N}$ helix apparently serves as a separate module from the Ras-like domain to interact with $\mathrm{G} \beta \gamma$, it is more amenable to generating functional chimeras ${ }^{28-30}$. Previous studies have shown that the entire $\alpha \mathrm{N}$ helix of $\mathrm{Ga}_{\mathrm{q}}, \mathrm{Ga}_{12}$ and $\mathrm{Ga}_{13}$ can be substituted with the corresponding region of $\mathrm{Ga}_{\mathrm{i} 1}$ to produce functional chimeric $\mathrm{G}_{\mathrm{i} / \mathrm{q}}, \mathrm{G}_{\mathrm{i} / 12}$ and $\mathrm{G}_{\mathrm{i} / 13}$. These engineered $G$ proteins retained the biochemical properties of their counterpart wild types, while $\alpha \mathrm{N}$ helix of $\mathrm{Ga}_{12 / 13}$ is reportedly important for the receptor selectivity ${ }^{31}$. Chimeric Gs protein has also been made with various lengths of $\alpha \mathrm{N}$ from Gai subunit to investigate the functional role of this region ${ }^{32,33}$. While the chimeras exhibit a large constitutive activity when the substitution goes beyond $\mathrm{aN}$ helix to replace the residues 1-62 of $\mathrm{Ga}_{\mathrm{s}}$ by 1-54 of $\mathrm{Ga}_{\mathrm{i}}$, a minor increase in the basal activity was observed when residues $1-41$ of $G \alpha_{s}$ is replaced by 1-34 of $\mathrm{Ga}_{\mathrm{i}}$. Our substitutions of $G_{\text {siN }}$ and $G_{11 \text { iN }}$ are both within the range of these chimeric designs and therefore would be expected to behave in the same way as the wild-type counterparts. In fact, our $G$ protein chimeras form functional heterotrimers with co-expressed $G \beta \gamma$ subunit and form stable and functional complexes with cognate GPCRs. The more conserved chimeras where the residues $1-18$ of $\mathrm{Ga}_{\mathrm{i} 1}$ is transferred to the equivalent residues of $G \alpha_{s}, G_{11}$ and $\mathrm{Ga}_{12}$ are also able to bind with Fab16 (Supplementary Fig. 2).

In conclusion, the antibody fragment derived from mAb16 promotes the stabilization of GPCR/G-protein complexes and adds an asymmetric feature that may aid with cryo-EM particle projection alignment. The usefulness of the antibody fragment in structural determination was proven by the cryo-EM structure of $\mu \mathrm{OR} / \mathrm{G}_{\mathrm{i} 1}$ complex where the presence of scFv16 stabilized the complex for high-resolution cryo-EM work. Furthermore, this antibody fragment can be applied to other G-protein subtypes with minimal protein engineering and therefore would be expected to be a broadly applicable tool for cryo-EM studies of any GPCR/G-protein complex.

\section{Methods}

Protein expression and purification. Rhodopsin/ $\mathrm{G}_{\mathrm{i} 1}$ complex was purified as described previously ${ }^{16}$. Briefly, bovine rhodopsin with three mutations, N2C, M257Y and N282C, was stably expressed in and purified from HEK293S GnTI cells using 1D4 immunoaffinity chromatography. Purified rhodopsin was incubated with $\mathrm{G}_{\mathrm{il}}$ reconstituted from recombinant Gail subunit from Escherichia coli BL21 (DE3) cells (Novagen) and G $\beta \gamma$ subunit purified from bovine retina (W L Lawson Company). Rhodopsin $/ \mathrm{G}_{\mathrm{i} 1}$ complex formation was triggered by the irradiation through $495 \mathrm{~nm}$ long-pass filter in the presence of apyrase (Sigma-Aldrich). Rhodopsin/ $\mathrm{G}_{\mathrm{i} 1}$ complex was separated from the free rhodopsin or $\mathrm{G}_{\mathrm{i} 1}$ by SEC on a Tricorn 10/600 column packed with Superdex 200 (GE healthcare) in a buffer containing $100 \mathrm{mM} \mathrm{NaCl}, 20 \mathrm{mM}$ Hepes pH 7.5, 0.01\% lauryl maltose neopentyl glycol (MNG), 2 mM 2-mercaptoethanol.

$\mu \mathrm{OR}$ with a cleavable amino and carboxy-terminal FLAG- and His-tag ${ }^{13}$ was expressed in Spodoptera frugiperda Sf9 insect cells using baculovirus infection system (Expression Systems). Cells were solubilized in $1 \% \mathrm{n}$-dodecyl- $\beta$-D-maltoside (DDM) (Anatrace), 0.2\% 5-cholesterol hemisuccinate (CHS) (Steraloids) and the soluble fraction was purified by Ni-chelating sepharose chromatography. The eluted protein was supplemented with $2 \mathrm{mM} \mathrm{CaCl}$, loaded onto M1 anti-FLAG immunoaffinity column (prepared in house) and washed with progressively lower concentrations of the antagonist naloxone (Sigma-Aldrich). Receptor was eluted in a buffer consisting of $100 \mathrm{mM} \mathrm{NaCl}, 20 \mathrm{mM}$ Hepes pH 7.5, 0.1\% DDM, $0.01 \%$ CHS with $50 \mathrm{nM}$ naloxone, and further purified by SEC on a Superdex 200 10/300 column in a buffer containing $1 \mu \mathrm{M}$ lofentanil (Tronto Research Chemicals) to exchange the ligand. Monomeric fractions were pooled, further supplemented with a twofold molar excess of lofentanil and concentrated to $\sim 100 \mu \mathrm{M}$ for complex formation. 
a


b

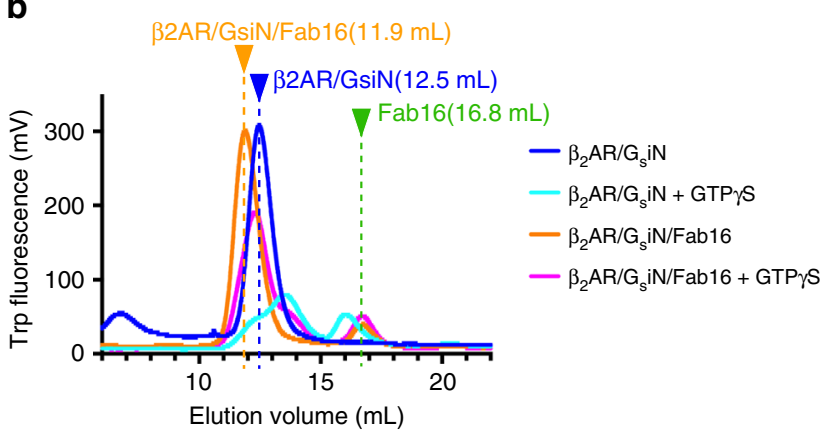

C



d



Fig. 5 Generation of chimeric G-proteins. a Alignment of the $\alpha \mathrm{N}$ helix of the $\mathrm{G}$-protein subfamilies and the sequence of the chimeric $\mathrm{G} \alpha$ subunits. Transferred region from $G \alpha_{i 1}$ in each chimera is colored in orange. b, c Analytical $S E C$ of $\beta 2 A R / G_{\text {sin }}$ and $M_{1} R / G_{11 i N}$ complexes incubated with GTP $\mathrm{S}$ in the presence or absence of Fab16. Protein elution profiles were monitored by the intrinsic tryptophan fluorescence. $\mathbf{d}$ Negative stain electron microscopy image of purified the $M_{1} R / G_{11 \mathrm{~N} N} /$ scFv16 complex

$\beta 2 \mathrm{AR}$ was purified in the same way as described previously ${ }^{34}$. Briefly, Sf9 insect cells were lysed by osmotic shock prior to solubilization of the membrane fraction by DDM. Solubilized receptor was first purified by M1 anti-FLAG immunoaffinity chromatography, followed by alprenolol-sepharose chromatograpy (alprenololsepharose resin prepared in house) to isolate only functional receptor. Alprenololsepharose eluate was concentrated on M1 FLAG affinity resin, and then washed with ligand-free buffer for $1 \mathrm{~h}$ at room temperature to eliminate bound alprenolol. Receptor was eluted in a buffer consisting of $20 \mathrm{mM}$ Hepes pH 7.5, $350 \mathrm{mM} \mathrm{NaCl}$, $0.1 \%$ DDM and $0.01 \%$ CHS and further purified by size-exclusion chromatography on a Superdex 200 10/300 column (GE Healthcare) in buffer containing $20 \mathrm{mM}$ Hepes pH 7.5, $100 \mathrm{mM} \mathrm{NaCl}, 0.05 \%$ DDM, 0.005\% CHS and 1 $\mu \mathrm{M}$ BI-167107 (Boehringer-Ingelheim). The eluated receptor was concentrated to $\sim 100 \mu \mathrm{M}$ for complexing.

For $\mathrm{M}_{1} \mathrm{R}$ and $\mathrm{M}_{2} \mathrm{R}$, we used constructs used in previous studies ${ }^{12,35}$ with some modifications. Briefly, T4L in the ICL3 of $M_{1} R$ was removed, and residues 219-232 and 345-354 were added to TM5 and TM6, respectively. The ICL3 of $\mathrm{M}_{2} \mathrm{R}$ was extended by 15 amino-acid residues from TM6. Primer sequences for these modifications are provided in the Supplementary Table. The amino-acid sequences for these receptors are provided in the Supplementary Note 2. These receptors were purified essentially in the same way as $\mu \mathrm{OR}$ with detergent exchange to MNG during M1 FLAG chromatography and using atropine (Sigma-Aldrich) and iperoxo (Sigma-Aldrich) in place of naloxone and lofentanil, respectively.

Heterotrimeric G-proteins were expressed and purified as previously described. Briefly, Trichuplusia ni (Hi5) insect cells (Expression Systems) were co-infected with two viruses, one encoding the wild-type human $\mathrm{G} \alpha$ subunit and another encoding the wild-type human $\beta 1 \gamma 2$ subunits with an decahistidine tag inserted at the amino terminus of the $\beta 1$ subunit with HRV-3C protease cleavable site. In the case of $G_{11 i N}$, additional virus encoding Ric8A was also co-infected. Cells were harvested $48 \mathrm{~h}$ post infection, lysed in hypotonic buffer and lipid-modified heterotrimeric G-protein was extracted in a buffer containing $1 \%$ sodium cholate (Sigma-Aldrich) and $0.05 \%$ DDM. The soluble fraction was purified using $\mathrm{Ni}$ chelating sepharose chromatography, and the detergent was exchanged from cholate/DDM mixture to DDM alone. After elution, HRV-3C protease (in-house prepared) was added and the protein was dialyzed against a buffer containing 20 mM Hepes pH 7.5, $100 \mathrm{mM} \mathrm{NaCl}, 1 \mathrm{mM} \mathrm{MgCl} 2,0.05 \%$ DDM, $100 \mu \mathrm{M}$ Tris(2carboxyethyl)phosphine hydrochloride (TCEP) (Sigma-Aldrich), $10 \mu \mathrm{M}$ GDP (Sigma-Aldrich). Cleaved heterotrimeric G-protein was further purified by reloading over Ni-sepharose resin. The flow through was collected and purified over a size-exclusion chromatography using a Superdex 200 10/300 column.

Soluble $G \beta \gamma$ subunit for crystallography was expressed and purified from Trichuplusia ni (Hi5) insect cells. Hi5 cells were infected with baculovirus encoding the human $\beta 1 \gamma 2$ subunits with cysteine 68 of $\gamma 2$ subunit mutated to serine $(\mathrm{G} \beta 1 \gamma 2 \mathrm{C} 68 \mathrm{~S})$ to remove the geranylgeranylation modification. A decahistidine tag was attached at the amino terminus of the $\beta 1$ subunit with HRV-3C protease cleavable site. Cultures were harvested $48 \mathrm{~h}$ post infection. Cells were lysed in the lysis buffer (10 mM Tris pH 7.4, $5 \mathrm{mM}$ 2-mercaptoethanol, $160 \mu \mathrm{g} / \mathrm{mL}$

benzamidine and $2.5 \mu \mathrm{g} / \mathrm{mL}$ leupeptin). Following to the centrifugation, the supernatant was incubated with Ni-chelating sepharose. The resin was first washed with a high salt buffer $(20 \mathrm{mM}$ Hepes $\mathrm{pH} 7.5,500 \mathrm{mM} \mathrm{NaCl}, 20 \mathrm{mM}$ imidazole and $2 \mathrm{mM} 2$-mercaptoethanol) then a low salt buffer $(20 \mathrm{mM}$ Hepes $\mathrm{pH} 7.5,100 \mathrm{mM}$ $\mathrm{NaCl}, 20 \mathrm{mM}$ imidazole and $100 \mu \mathrm{M}$ TCEP). The protein was eluted with an elution buffer $(20 \mathrm{mM}$ Hepes $\mathrm{pH} 7.5,100 \mathrm{mM} \mathrm{NaCl}, 250 \mathrm{mM}$ imidazole and 100 $\mu \mathrm{M}$ TCEP) and dialysed against $20 \mathrm{mM}$ Hepes pH 7.5, $100 \mathrm{mM} \mathrm{NaCl}$ and $100 \mu \mathrm{M}$ TCEP after adding HRC-3C protease to cleave amino-terminal His-tag. G $\beta 1$ 2 2 C68S was further purified by reloading over Ni-sepharose resin. The flow through was collected and purified by a size-exclusion chromatography using a Superdex 200 10/300 column.

The human $\mathrm{Ga}_{\mathrm{il}}$ protein for crystallography was expressed in Escherichia coli Rosetta2 (DE3) cells (Novagen) with an N-terminal octahistidine-tag and an HRV$3 \mathrm{C}$ protease recognition site. The culture was grown at $37^{\circ} \mathrm{C}$ in $\mathrm{TB}$ medium. When the OD 600 reached 0.6 , the protein expression was induced with $0.5 \mathrm{mM}$ IPTG and further grown for $20 \mathrm{~h}$ at $24^{\circ} \mathrm{C}$. The cells were harvested by centrifugation, resuspended in the lysis buffer $(50 \mathrm{mM}$ Tris- $\mathrm{HCl}, \mathrm{pH} 7.5,100 \mathrm{mM} \mathrm{NaCl}, 10 \mathrm{mM}$ imidazole, $0.1 \mathrm{mM}$ PMSF, $10 \mu \mathrm{M}$ GDP and $5 \mathrm{mM}$ 2-mercaptoethanol). The resuspended cells were disrupted by sonication. Cell lysate was clarified by centrifugation and the supernatant was incubated with Ni-chelating sepharose equilibrated with the lysis buffer. The resin was first washed with the high salt buffer ( $20 \mathrm{mM}$ Hepes pH 7.5, $500 \mathrm{mM} \mathrm{NaCl}, 1 \mathrm{mM} \mathrm{MgCl} 2,20 \mathrm{mM}$ imidazole, 10 $\mu \mathrm{M}$ GDP and $2 \mathrm{mM}$ 2-mercaptoethanol) then the low salt buffer (20 mM Hepes $\mathrm{pH}$ $7.5,100 \mathrm{mM} \mathrm{NaCl}, 1 \mathrm{mM} \mathrm{MgCl}, 20 \mathrm{mM}$ imidazole, $10 \mu \mathrm{M}$ GDP and $100 \mu \mathrm{M}$ TCEP). The protein was eluted with the elution buffer ( $20 \mathrm{mM}$ Hepes $\mathrm{pH} 7.5,100$ $\mathrm{mM} \mathrm{NaCl}, 1 \mathrm{mM} \mathrm{MgCl} 2,250 \mathrm{mM}$ imidazole, $10 \mu \mathrm{M}$ GDP and $100 \mu \mathrm{M}$ TCEP) and dialysed against $20 \mathrm{mM}$ Hepes $\mathrm{pH} 7.5,100 \mathrm{mM} \mathrm{NaCl}, 1 \mathrm{mM} \mathrm{MgCl} 2,10 \mu \mathrm{M}$ GDP and $100 \mu \mathrm{M}$ TCEP after adding HRC-3C protease to cleave amino-terminal tag. Cleaved $\mathrm{Ga}_{\mathrm{i} 1}$ was further purified by reloading over $\mathrm{Ni}$-sepharose resin. The flow through was collected and purified over a size-exclusion chromatography using a Superdex 200 10/300 column.

GPCR/G-protein complex was prepared essentially in the same way as described previously using agonists lofentanil, iperoxo, BI-167107 for $\mu \mathrm{OR}, \mathrm{M}_{1} \mathrm{R}$ and $\mathrm{M}_{2} \mathrm{R}, \beta 2 \mathrm{AR}$, respectively ${ }^{2}$. Briefly, receptor was mixed with $1.2-1.5$ molar excess G-protein. Following the incubation at room temperature for $1 \mathrm{~h}$, apyrase was added and the reaction mixture was transferred to $4^{\circ} \mathrm{C}$ and further incubated for $4 \mathrm{~h}$ to overnight. Prior to loading M1 FLAG column, $1 \%$ MNG and $0.1 \%$ CHS was added. The MNG concentration was progressively lowered during M1 FLAG wash. FLAG eluted protein was further purified by size-exclusion chromatography on a Superdex 200 10/300 column.

Monoclonal antibody production and characterization. For the antigen, rhodopsin- $\mathrm{G}_{\mathrm{i} 1}$ complex was stabilized by crosslink using BS-3 (ThermoFisher). Naval Medical Research Institute (NMRI) mice were immunized intraperitoneally with the emulsified antigen. (This study was carried out in strict accordance with the Rules and Regulations for the Protection of Animal Rights (Tierschutzverordnung) of the Swiss Bundesamt für Veterinärwesen. The protocol was ethically approved by the Ethikkommission beider Basel (Permit Number: 237/23523).) Mice with strong ELISA reaction to the antigen were killed and the spleen was removed. Isolated splenocytes were fused with the myeloma cell partner (PAI 
mouse myeloma cells, derived from P3-x63-AG8) using polyethylene glycol 1500 (Roche Diagnostics). The fusion mixture was plated into multi-well plates (Thermo Scientific Nunc MicroWell Cell Culture High Flange 96-Well Microplates) and clonal hybridomas were selected by growing in HAT medium supplemented with culture supernatant of mouse macrophages P388. IgG positive clones were screened by ELISA for reactivity against Rhodopsin/ $\mathrm{G}_{\mathrm{i} 1}$ complex. Clones that showed a positive reaction in an ELISA assay and by immunoprecipitation were further characterized as monoclonal antibodies or Fab fragments. Initial SEC analysis using rhodopsin $/ \mathrm{G}_{\mathrm{i} 1}$ or each component was carried out in $20 \mathrm{mM}$ Hepes $\mathrm{pH} 7.5$, $100 \mathrm{mM} \mathrm{NaCl}, 2 \mathrm{mM}$ 2-mercaptethanol and 0.01\% MNG using Superdex 200 10/200 column.

Coding regions of the heavy-chain (VH-CH1) and light-chain (VL-CL) of mAb16 were cloned into the modified pVL1392 vector where VH-CH1 and VL-CL both attached with GP67 secretion signal sequence were under polyhedron and p10 promoter regulation, respectively. Octahistidine-tag with HRV-3C protease cleavable site was attached to the carboxy-terminus of $\mathrm{VH}-\mathrm{CH} 1$ for the purification. The single-chain variable fragment of mAb16 (scFv16) was cloned into a modified pVL1392 vector containing a GP67 secretion signal immediately prior to the amino terminus of the scFv16. Octahistidine-tag with HRV-3C protease cleavable site was attached to the carboxy-terminus.

Both Fab16 and scFv16 were expressed in secreted form from Trichuplusia ni Hi5 insect cells using the baculovirus infection method (Expression Systems), and purified by Ni-sepharose chromatography. Supernatant from baculovirus infected cells was $\mathrm{pH}$ balanced by addition of Tris $\mathrm{pH}$ 7.5. Chelating agents were quenched by addition of $1 \mathrm{mM}$ nickel chloride and $5 \mathrm{mM}$ calcium chloride and incubation with stirring for $1 \mathrm{~h}$ at $25^{\circ} \mathrm{C}$. Resulting precipitates were removed by centrifugation and the supernatant was loaded over Ni-sepharose chromatography column. The column was washed with a high salt buffer (20 mM Hepes pH 7.5, $500 \mathrm{mM} \mathrm{NaCl}$ and $20 \mathrm{mM}$ imidazole) followed by a low salt buffer (20 mM Hepes pH 7.5, $100 \mathrm{mM} \mathrm{NaCl}$ and $20 \mathrm{mM}$ imidazole). The protein was eluted with the elution buffer $(20 \mathrm{mM}$ Hepes pH 7.5, $100 \mathrm{mM} \mathrm{NaCl}$ and $250 \mathrm{mM}$ imidazole) and the carboxy-terminal octahistidine tag was cleaved by incubation with HRV-3C protease during dialysis against a buffer consisting of $20 \mathrm{mM}$ Hepes $\mathrm{pH} 7.5$ and $100 \mathrm{mM} \mathrm{NaCl}$. Cleaved protein was further purified by reloading over Ni-NTA resin. The flow through was collected and purified over a size-exclusion chromatography using a Superdex 200 16/60 column (GE healthcare). Monomeric fractions were pooled, concentrated and flash frozen in liquid nitrogen until use.

For the binding assay of Fab16 with heterotrimeric G-protein subtypes, Fab16 was first labelled with Alexa Fluor 488 NHS Ester (ThermoFisher Scientific) in $20 \mathrm{mM}$ MES pH 6.5. Free dye was removed by G-50 desalting column (GE healthcare), and the labelled Fab16 was recovered and concentrated. 5-30 $\mu \mathrm{M}$ of Gprotein was mixed with $0.4 \mu \mathrm{M}$ of labelled Fab16, incubated for $1 \mathrm{~h}$ and run on SEC on a Superdex 200 10/300 column. Fluorescence signal was recorded with excitation at $488 \mathrm{~nm}$ and emission at $512 \mathrm{~nm}$.

Construction of chimeric $\mathbf{G}$ proteins. $\mathrm{Ga}_{\mathrm{siN}}$ was constructed by substituting the residues $1-38$ of $\mathrm{Ga}_{\mathrm{s}}$ with the residues $1-31$ of $\mathrm{Ga}_{\mathrm{i1}}$. $\mathrm{Ga}_{11 \mathrm{iN}}$ were constructed by substituting the residues 1-36 of $\mathrm{Ga}_{11}$ with the residues 1-29 of $\mathrm{Ga}_{\mathrm{i1}}$. These constructs were cloned into $\mathrm{pFastBacl}$ vector and baculovirus were made according to the manufacturer. Scanning chimeras of Ga11 as well as $\mathrm{Ga}_{\mathrm{siN} 18}, \mathrm{Ga}_{11 \mathrm{iN} 18}$ and Ga12 $2_{\mathrm{iN} 18}$ are also made in the same way. Primer sequences used to construct the chimeras are provided in the Supplementary Table. The amino-acid sequences of the chimera constructs are provided in the Supplementary Note 2.

Characterizing resistance to GTP $\gamma \mathbf{S}$. GTP $\gamma \mathrm{S}$ resistance test was performed in the buffer containing $20 \mathrm{mM}$ Hepes pH7.5, $100 \mathrm{mM} \mathrm{NaCl}, 100 \mu \mathrm{M}$ TCEP, $0.01 \%$ MNG, with each agonist for the complex, lofentanil, iperoxo, BI167107 for $\mu \mathrm{OR} /$ $G_{i 1}, M_{1} R / G_{11 i N}$ and $M_{2} R / G_{0 A}, \beta 2 A R / G_{\text {siN }}$, respectively. Purified complex with or without Fab16 was incubated with $100 \mu \mathrm{M}$ GTP $\gamma \mathrm{S}$ in the buffer and incubated for $1 \mathrm{~h}$ at $24^{\circ} \mathrm{C}$ followed by SEC analysis on Superdex $20010 / 300$ monitoring the protein intrinsic fluorescence with the excitation wavelength at $280 \mathrm{~nm}$ and emission wavelength $340 \mathrm{~nm}$.

Determination of the structure of the $\mathbf{G}_{\mathbf{i 1}} / \mathbf{s c F v 1 6}$ complex. For $\mathrm{G}_{\mathrm{i1}} / \mathrm{scFv} 16$ crystallization, separately purified and concentrated $\mathrm{Ga}_{\mathrm{i}}, \mathrm{G} \beta 1 \gamma 2 \mathrm{C} 68 \mathrm{~S}$ and $\mathrm{scFv} 16$ were mixed at a 1:1:1.2 molar ratio and incubated for $30 \mathrm{~min}$ at $24^{\circ} \mathrm{C}$. The resulting $\mathrm{G}_{\mathrm{i1}} / \mathrm{scFv} 16$ complex was purified from uncomplexed subunits and free scFv16 by SEC in the buffer containing $20 \mathrm{mM}$ Hepes pH7.5, $100 \mathrm{mM} \mathrm{NaCl}, 1 \mathrm{mM} \mathrm{MgCl}$, $10 \mu \mathrm{M}$ GDP and $100 \mu \mathrm{M}$ TCEP. Purified $\mathrm{G}_{\mathrm{i} 1} / \mathrm{scFv} 16$ was incubated with $1 \mathrm{mM}$ aluminium chloride and $50 \mathrm{mM}$ sodium fluoride for $1 \mathrm{~h}$ on ice, concentrated to $10-15 \mathrm{mg} / \mathrm{mL}$ and crystallized using the hanging drop vapour diffusion method at $20^{\circ} \mathrm{C}$ against a reservoir solution containing $10 \%$ PEG 8000, $0.1 \mathrm{M}$ Sodium citrate pH 5.0, $1 \mathrm{mM} \mathrm{MgCl}_{2}, 10 \mu \mathrm{M}$ GDP, $100 \mu \mathrm{M}$ TCEP, $1 \mathrm{mM}$ aluminium chloride and $10 \mathrm{mM}$ sodium fluoride. Crystals appeared within a few hours and grew to the full size in 5 days. Crystals were soaked into the reservoir solution supplemented with $25 \%$ glycerol as a cryo-protectant and flash frozen in liquid nitrogen. The X-ray data set was collected at the experimental station 12-2 in the Stanford Synchrotron Radiation Lightsource. Diffraction data were integrated by $\mathrm{XDS}^{36}$, scaled and merged by AIMLESS ${ }^{37}$. The structure was solved by the molecular replacement in Phaser ${ }^{38}$ using the heterotrimeric Gi-protein (1GP2) and scFv fragment (4NKD) as independent search models. Manual model building was performed in $\operatorname{Coot}^{39}$ and refinement was performed with Phenix refine $e^{40,41}$. Ramachandran statistics are favoured $96.6 \%$, allowed $3.4 \%$, outlier $0.0 \%$.

Nucleotide-binding studies. For the nucleotide-binding experiment, fluorescence from BODIPY-FL-GTP $\gamma$ S or BODIPY-FL-GDP (ThermoFisher Scientific) was recorded using the Fluorolog spectrophotometer (HORIBA) in the $500 \mu \mathrm{L}$ quartz cuvette. The fluorophore was exited at $495 \mathrm{~nm}$ and emission was detected at $508 \mathrm{~nm}$ at $22^{\circ} \mathrm{C}$. The buffer composition is $20 \mathrm{mM}$ HEPES, pH 7.5, $100 \mathrm{mM}$ sodium chloride, $0.01 \%$ LMNG, $10 \mathrm{mM}$ magnesium chloride, $100 \mu \mathrm{M}$ TCEP and $10 \mu \mathrm{M}$ iperoxo or BI-167107 for GPCR/G-protein complexes, and $20 \mathrm{mM}$ HEPES, $\mathrm{pH} 7.5,100 \mathrm{mM}$ sodium chloride, $0.02 \% \mathrm{DDM}, 10 \mathrm{mM}$ magnesium chloride, $100 \mu \mathrm{M}$ TCEP for Gil. Kinetics data were collected with $1 \mu \mathrm{M}$ fluorophore alone for $100 \mathrm{~s}$ to establish the baseline fluorescence intensity. Protein was added to $200 \mathrm{nM}$ and rapidly mixed in the fluorescence cuvette. Data points were acquired every second for $600 \mathrm{~s}$. The resulting kinetics spectra were plotted and fit to one phase- or two phase-association function using GraphPad Prism 7.0.

Data availability. Data supporting the findings of this manuscript are available from the corresponding authors upon reasonable request. Structure and data set in this work have been deposited in the Protein Data Bank under accession code PDB 6CRK.

Received: 26 March 2018 Accepted: 25 July 2018

Published online: 13 September 2018

\section{References}

1. Hauser, A. S., Attwood, M. M., Rask-Andersen, M., Schiöth, H. B. \& Gloriam, D. E. Trends in GPCR drug discovery: new agents, targets and indications. Nat. Rev. Drug. Discov. 16, 829 EP (2017).

2. Rasmussen, S. G. F. et al. Crystal structure of the [bgr]2 adrenergic receptorGs protein complex. Nature 477, 549-555 (2011).

3. Kang, Y. et al. Crystal structure of rhodopsin bound to arrestin by femtosecond X-ray laser. Nature 523, 561-567 (2015).

4. Carpenter, B., Nehmé, R., Warne, T., Leslie, A. G. W. \& Tate, C. G. Structure of the adenosine $\mathrm{A}(2 \mathrm{~A})$ receptor bound to an engineered $\mathrm{G}$ protein. Nature 536, 104-107 (2016).

5. Liang, Y.-L. et al. Phase-plate cryo-EM structure of a class B GPCR-G-protein complex. Nature 546, 118-123 (2017).

6. Zhang, Y. et al. Cryo-EM structure of the activated GLP-1 receptor in complex with a G protein. Nature 546, 248-253 (2017)

7. Liang, Y.-L. et al. Phase-plate cryo-EM structure of a biased agonist-bound human GLP-1 receptor-Gs complex. Nature 555, 121-125 (2018).

8. Choe, H.-W. et al. Crystal structure of metarhodopsin II. Nature 471, 651-655 (2011).

9. Rose, A. S. et al. Position of transmembrane helix 6 determines receptor $\mathrm{g}$ protein coupling specificity. J. Am. Chem. Soc. 136, 11244-11247 (2014).

10. Flock, T. et al. Selectivity determinants of GPCR-G-protein binding. Nature 545, 317-322 (2017).

11. Rasmussen, S. G. F. et al. Structure of a nanobody-stabilized active state of the [bgr]2 adrenoceptor. Nature 469, 175-180 (2011).

12. Kruse, A. C. et al. Activation and allosteric modulation of a muscarinic acetylcholine receptor. Nature 504, 1998-2003 (2013).

13. Huang, W. et al. Structural insights into $\mu$-opioid receptor activation. Nature 524, 315-321 (2015).

14. Che, T. et al. Structure of the nanobody-stabilized active state of the kappa opioid receptor. Cell 172, 55-67.e15 (2018).

15. Koehl, A. et al. Structure of the $\mu$-opioid receptor-Gi protein complex. Nature 558, 547-552 (2018).

16. Maeda, S. et al. Crystallization scale preparation of a stable GPCR signaling complex between constitutively active rhodopsin and G-protein. PLoS ONE $\mathbf{9}$, e98714 (2014)

17. Van Eps, N. et al. Interaction of a $G$ protein with an activated receptor opens the interdomain interface in the alpha subunit. Proc. Natl Acad. Sci. USA 108, 9420-9424 (2011).

18. Westfield, G. H. et al. Structural flexibility of the G s -helical domain in the 2adrenoceptor Gs complex. Proc. Natl Acad. Sci. USA 108, 16086-16091 (2011).

19. Stura, E. A., Fieser, G. G. \& Wilson, I. A. Crystallization of antibodies and antibody-antigen complexes. Immunomethods 3, 164-179 (1993).

20. Sunahara, R. K. Crystal structure of the adenylyl cyclase activator Gs. Science 278, 1943-1947 (1997). 
21. Mixon, M. B. et al. Tertiary and quaternary structural changes in gialpha induced by GTP hydrolysis. Science 270, 954-960 (1995).

22. Coleman, D. et al. Structures of active conformations of Gi alpha 1 and the mechanism of GTP hydrolysis. Science 265, 1405-1412 (1994).

23. Van Eps, N., Oldham, W. M., Hamm, H. E. \& Hubbell, W. L. Structural and dynamical changes in an -subunit of a heterotrimeric $\mathrm{G}$ protein along the activation pathway. Proc. Natl Acad. Sci. USA 103, 16194-16199 (2006).

24. Brandt, D. R. \& Ross, E. M. GTPase activity of the stimulatory GTP-binding regulatory protein of adenylate cyclase, Gs. Accumulation and turnover of enzyme-nucleotide intermediates. J. Biol. Chem. 260, 266-272 (1985).

25. Chung, K. Y. et al. Conformational changes in the $\mathrm{G}$ protein Gs induced by the [bgr]2 adrenergic receptor. Nature 477, 611-615 (2011).

26. Medkova, M., Preininger, A. M., Yu, N.-J., Hubbell, W. L. \& Hamm, H. E. Conformational changes in the amino-terminal helix of the $\mathrm{G}$ protein alpha (i1) following dissociation from Gbetagamma subunit and activation. Biochemistry 41, 9962-9972 (2002).

27. Downes, G. B. \& Gautam, N. The G protein subunit gene families. Genomics 62, 544-552 (1999).

28. Tesmer, V. M., Kawano, T., Shankaranarayanan, A., Kozasa, T. \& Tesmer, J. J. G. Snapshot of activated G proteins at the membrane: the Galphaq-GRK2Gbetagamma complex. Science 310, 1686-1690 (2005).

29. Kreutz, B. et al. A new approach to producing functional ga subunits yields the activated and deactivated structures of $\mathrm{Ga} 12 / 13$ proteins. Biochemistry 45, 167-174 (2006).

30. Nishimura, A. et al. Structural basis for the specific inhibition of heterotrimeric Gq protein by a small molecule. Proc. Natl Acad. Sci. USA 107, 13666-13671 (2010).

31. Yamaguchi, Y., Katoh, H. \& Negishi, M. N-terminal short sequences of alpha subunits of the G12 family determine selective coupling to receptors. J. Biol. Chem. 278, 14936-14939 (2003).

32. Osawa, S., Dhanasekaran, N., Woon, C. W. \& Johnson, G. L. G alpha i-G alpha s chimeras define the function of alpha chain domains in control of $G$ protein activation and beta gamma subunit complex interactions. Cell 63, 697-706 (1990).

33. Russell, M. \& Johnson, G. L. G protein amino-terminal alpha i2/alpha s chimeras reveal amino acids important in regulating alpha s activity. Mol. Pharmacol. 44, 255-263 (1993).

34. Gregorio, G. G. et al. Single-molecule analysis of ligand efficacy in $\beta 2 A R-G-$ protein activation. Nature 547, 68-73 (2017)

35. Thal, D. M. et al. Crystal structures of the M1 and M4 muscarinic acetylcholine receptors. Nature 531, 7282-7287 (2016).

36. Kabsch, W. XDS. Acta Crystallogr. D Biol. Crystallogr. 66, 125-132 (2010).

37. Evans, P. Scaling and assessment of data quality. Acta Crystallogr. D Biol. Crystallogr. 62, 72-82 (2006)

38. McCoy, A. J. et al. Phaser crystallographic software. J. Appl. Crystallogr. 40 658-674 (2007).

39. Emsley, P., Lohkamp, B., Scott, W. G. \& Cowtan, K. Features and development of Coot. Acta Crystallogr. D Biol. Crystallogr. 66, 486-501 (2010).

40. Adams, P. D. et al. PHENIX: a comprehensive Python-based system for macromolecular structure solution. Acta Crystallogr. D Biol. Crystallogr. 66, 213-221 (2010).

41. Afonine, P. V. et al. Towards automated crystallographic structure refinement with phenix.refine. Acta Crystallogr. D Biol. Crystallogr. 68, 352-367 (2012).
42. Flock, T. et al. Universal allosteric mechanism for Ga activation by GPCRs. Nature 524, 173-179 (2015).

\section{Acknowledgements}

We thank Jean-Philippe Carralot (F. Hoffmann-La Roche Ltd) for help in antibody generation, Martin Siegrist, Georg Schmid, Bernard Rutten, Doris Zulauf, Stephanie

Kueng (Roche Non-Clinical Biorepository) and Ralf Thoma for technical assistance for biomass and cell line generation. Shoji Maeda was supported by the Roche Postdoctoral Fellowship (RPF ID: 113). This work was supported by NIH grant R01GM083118 to B.K. K. B.K.K. is a Chan Zuckerberg Biohub investigator.

\section{Author contributions}

S.M. prepared rhodopsin/Gil complex for immunization and selection, performed mAb characterization, $\mathrm{Fab}$ and scFv cloning, expression and purification with assistance from A.M., prepared $M_{1} R / G_{11 i N}, M_{2} R / G_{o A}, \beta 2 A R / G_{s i N}$, performed Gil/scFv16 crystallization, structure determination and characterization. A.K. prepared $\mu \mathrm{OR} / \mathrm{G}_{i 1}$. H.M. performed immunization and antibody selection with assist from R.J.P.D. H.H. performed negative stain EM visualization. D.H. prepared $\beta 2 \mathrm{AR} / \mathrm{G}_{\mathrm{s}}$ and provided advice for G-protein experiments. G.S. provided advice on EM analysis and interpretation. G.F.X.S initiated the project. R.J.P.D., and B.K.K. supervised the project.

\section{Additional information}

Supplementary Information accompanies this paper at https://doi.org/10.1038/s41467 018-06002-w.

Competing interests: B.K.K. is a co-founder of and consultant for ConfometRx. R.J.P.D is employed by Roche Pharmaceuticals. The remaining authors declare no competing interests.

Reprints and permission information is available online at http://npg.nature.com/ reprintsandpermissions/

Publisher's note: Springer Nature remains neutral with regard to jurisdictional claims in published maps and institutional affiliations.

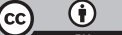

Open Access This article is licensed under a Creative Commons Attribution 4.0 International License, which permits use, sharing, adaptation, distribution and reproduction in any medium or format, as long as you give appropriate credit to the original author(s) and the source, provide a link to the Creative Commons license, and indicate if changes were made. The images or other third party material in this article are included in the article's Creative Commons license, unless indicated otherwise in a credit line to the material. If material is not included in the article's Creative Commons license and your intended use is not permitted by statutory regulation or exceeds the permitted use, you will need to obtain permission directly from the copyright holder. To view a copy of this license, visit http://creativecommons.org/ licenses/by/4.0/.

(c) The Author(s) 2018 